\title{
Performance Evaluation of Newly Developed Sustainable Blocks for Affordable Housing in Malaysia
}

\author{
Ashwin Narendra Raut ${ }^{1,2 *}$, Christy Pathrose Gomez ${ }^{2}$ \\ ${ }^{1}$ Department of Civil Engineering, Lords Institute of Engineering and Technology, India \\ ${ }^{2}$ Department of Construction Management, Universiti Tun Hussien Onn Malaysia, Johor, Malaysia
}

\begin{abstract}
The thermal design of affordable housing in Malaysia could be ineffective and resulting from this, the majority of their occupants are not satisfied with the thermal comfort levels provided. To overcome this issue of thermal performance of building envelope, the development of sustainable blocks has been done. The blocks have been developed using locally available sustainable waste materials. The materials utilized were mainly procured from agro-industrial waste (oil palm industry) and municipal waste (waste glass). The aim of the research was to provide a better performing material for low cost houses replacing the conventional red clay bricks. In this research, the physical, mechanical and thermal performance of the sustainable building blocks were examined and compared with existing conventional building blocks. The experimental findings revealed that the newly developed Sustainable blocks have better thermal performance as compared to conventional burnt clay bricks. However, the physico-mechanical performance complies with various standard practices thus proving to be a sustainable wall material.
\end{abstract}

\section{Introduction}

Construction activities are one the major contributors causing environmental pollution. Additionally, it is evident that the construction sector consumes large quantity of ecological resources, resulting in serious negative environmental impacts. Thus, many private and government agencies are focusing on sustainable construction practices to overcome the negative environmental hazards caused by the construction sector. However, the current efforts towards sustainable practices are still found to be lacking. Emphasis on green building concepts for sustainable development is acknowledged to be a key aspect in reducing adverse environmental impact [1].

In the Tenth Malaysian Plan, it is stated that continuous efforts will be put into ensuring citizens of Malaysia of all income groups can have the opportunity to acquire hous es that are frequently referred to as "adequate, affordable and of good quality." Currently the is sue of housing is found to be more crucial in urban areas, greater emphasis is placed on the low-income group for better urban services and healthy living [2]. The Malaysian government has a requirement that for all private development, $30 \%$ of housing units should be of the low-cost housing type. Otherwise, the developer will have to pay the 
government the cost of building those units, if so agreed. Studies bas ed on the various Malaysia Plans have shown that the government has been continuously encouraging the private sector to develop more low-cost houses and low-medium-cost houses. Currently, there is a huge demand and provision of low-income housing in Malaysia, which is being satis fied mainly by government policy. Although the Malaysian government's commitment is stated to be the provision of quality and affordable housing, the aspect of indoor comfort is noted to be unsatisfactory [3]. Low-cost housing (LCH) is perceived to have a lower standard of housing, and in trying to provide affordable housing, the standard of houses is always being compromised. There is certainly a need for providing a sustainable solution in providing better indoor air comfort levels, which is best done by utilizing sustainable locally available resources (materials).

It is important to improve the thermal performance of the building envelope to improve the indoor comfort levels of the spaces within the building envelope. Building envelopes with better thermal performance retains internal heat, thus maintaining the lower temperature values considering hot climatic conditions outside during the day [4]. The majority of the building envelopes of low-cost housing are covered by walls composed of either clay or cement brick/block assembly. Thus, it is very crucial to have bricks with better thermal performance. A number of methods are used in order to achieve better thermal performance of the building envelope, enhancement of thermal performance can be done by adding pore forming additives in the composition of bricks. The porous additives are mostly light weight in nature. The additives contribute towards the porosity of the final product, which contributes towards a lower rate of heat transfer. Some of the previous researches also focused on the enhancement of thermal performance of build ing materials especially bricks. Previous research has emphasised on the utilization of contribution of agricultural, municipal and industrial waste to achieve sustainable practices.

Oti et. al. [5] utilized Ground Granulated Blast Furnace Slag (GGBS) as a supplementary cementitious binder along with portland cement and quick lime to develop two varieties of unfired clay bricks. The observed mean thermal values for developed product was found to be $0.2545 \mathrm{~W} / \mathrm{mK}$ and $0.2612 \mathrm{~W} / \mathrm{mK}$ using the lime and cement binder specimens respectively. It was concluded that the thermal conductivity values was a function of material density and moisture content. In another research, Khedari et. al. [6] utilized coconut coir fibers to develop soil-cement block to attain the lower values of thermal conductivity. The properties observed were thermal conductivity and compressive strength having values of $0.651 \mathrm{~W} / \mathrm{mK}$ and $39.55 \mathrm{~kg} / \mathrm{cm}^{2}$. It was concluded that the lower rate of heat transfer in the material was due to the addition of fibers; however, fiber addition also resulted in lowering of compressive strength.

Turgut [7] studied the performance of bricks developed from combination of glass powder and limestone along with class-C fly ash. The performance of various properties such as water absorption, density, compressive and flexural strengths, and thermal conductivity of the bricks were calculated. Findings showed that the glass powder content enhanced the thermal performance of bricks, due to the fact that thermal conductivity value of glass was found to be approximately $0.96 \mathrm{~W} / \mathrm{mK}$. In addition to that the positive rise in the compressive and flexural strength of the bricks containing glass powder were observed.

Binci et. al. [8] studied the fiber reinforced mud bricks for thermal performance and mechanical properties in compliance with ASTM and Turkish Standards. The results showed low thermal conductivity values of $0.2 \mathrm{~W} / \mathrm{mK}$ due to the addition of straw. Similarly, Alami [9] utilized fibrous materials such as olive husk and straw as a filler in clay bricks. The addition of $40 \%$ olive husk and $10 \%$ straw showed a thermal conductivity ( $\lambda$ ) value of $0.09 \mathrm{~W} / \mathrm{mK}$.

Bal et. al. [10] analysed the thermal performance of bricks developed from millet waste mixed with laterite powder. Due to the incorporation of millet waste the thermal 
performance values reduced from $1.4 \mathrm{~W} / \mathrm{mK}$ to $0.29 \mathrm{~W} / \mathrm{mK}$ for dry laterite soil bricks. Whilst Zach et. al. [11] described the use of Polyurethane (PUR) waste of fraction 3-6 mm and Expanded Polystyrene (EPS) waste of fraction 1-4 mm. The PUR and EPS were mixed in 50:50 proportions, but the samples were cured at three different set of temperatures. The thermal conductivity values were found to be around $0.035 \mathrm{~W} / \mathrm{mK}$.

Focusing on the use of Rice Husk Ash (RHA), Lertsatitthanakorn et. al. [12] analysed the thermal performance of RHA based sand-cement block as per JIS R 2618 [13]. The comparative results of RHA bricks with commercially available clay bricks showed a significant reduction in thermal conductivity values. It was found that the thermal performance of RHA bricks was $54 \%$ better than that of commercial clay bricks. Meukam et. al. [14] performed an experimental study on the influence of addition of a pozzolan namely sawdust in lateritic soil bricks. The partial replacement of sawdust was performed in the Lateritic soil along with cement in $9 \% \mathrm{wt}$. proportion. It was found that the developed bricks had thermal conductivity of $0.34 \mathrm{~W} / \mathrm{mK}$ and $0.36 \mathrm{~W} / \mathrm{mK}$ by using the flash method and box method respectively.

Wang et. al. [15] analysed the influence of pore structure on the thermal performance of material and its lightweight characteristics. They studied the influence of pores generated from hydration of sewage sludge ash with cement along with metallic alumina powder. Analysis was performed on the pore generated from hydration of sewage sludge ash along with metallic alumina powder. Due to the enanced pores developed from the addition of sewage sludge ash, the thermal conductivity was lower and the values were in between 0.085 to $0.102 \mathrm{~W} / \mathrm{mK}$. Having conducted an extensive literature review it was decided that by tackling the problem of improving the thermal performance of the building envelope in low-cost housing with the aim of obtaining a sustainable solutiong, using waste material is the best solution. Hence, this paper describes the evaluation of the performance of bricks and mortar developed from various types of waste generated from agro-industrial as well as municipal activities. The performance of developed prototype was evaluated by comparing its physico-mechanical and thermal properties with the commercially available clay bricks and mortar. Furthermore, the thermal performance was evaluated based on the comparative heat transfer analysis of developed prototype brick wall system with commercially available clay brick wall system.

\section{Methodology}

\subsection{Raw Materials}

The materials used for development of bricks were glass powder, palm oil fly ash, oil palm fibers, crusher dust and Lime. The materials for the development of sustainable bricks were obtained from nearby sources to reduce the transportation and energy cost; the samples used are shown in fig. 1 . The waste glass was procured from a nearby municipal dump yard to the university (Universiti Tun Hussein Onn Malaysia, Batu Pahat, Johor) where the research was undertaken. Whereas, the oil palm waste was procured from Kian Hoe Plantations, within a $20 \mathrm{~km}$ radius from the university. The primary raw material was mainly sustainable in nature ; whereas, for binding material, lime was used as an alternative to the traditional energy consumptive cement. The X-ray Fluorescence (XRF) test was performed on the raw materials to identify their chemical composition. The test results of chemical analysis is presented in Table 1. 


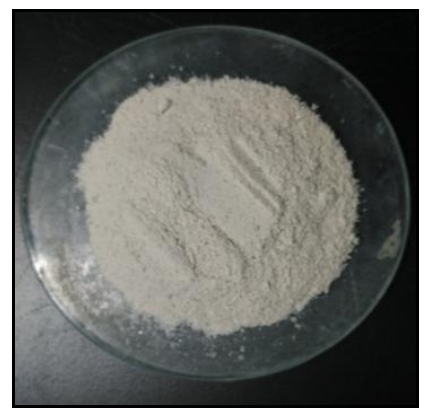

(a) Glass Powder

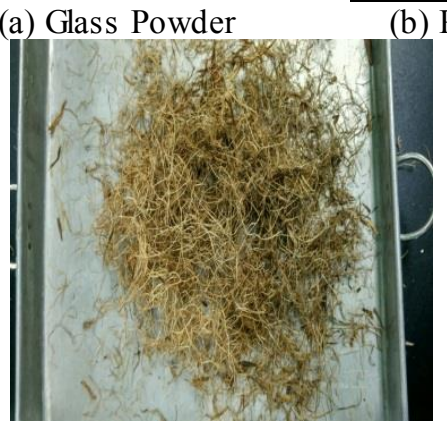

(d) Oil Palm Fibers

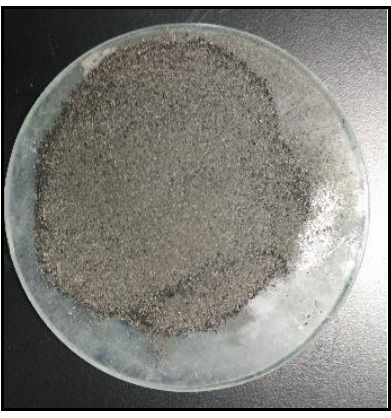

(b) Palm Oil Fly Ash

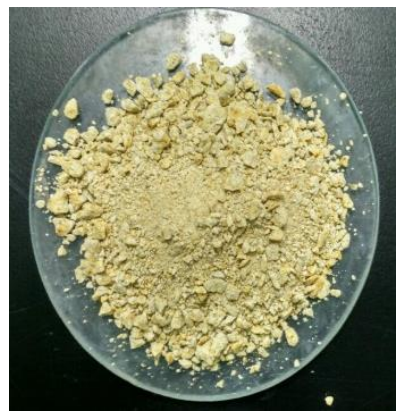

(c) Crusher dust

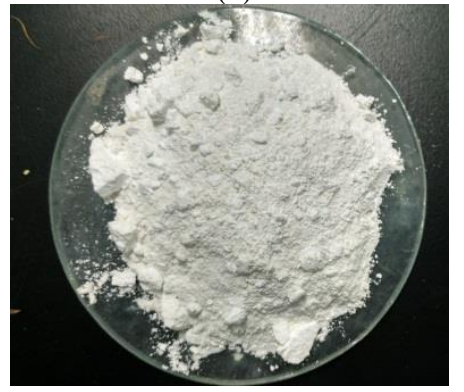

(e) Lime

Fig 1. Raw materials used for TESH BRICK

Table 1. Chemical composition of glass powder, palm oil fly ash and lime

\begin{tabular}{ccccccccccc}
\hline $\begin{array}{l}\text { Chemical } \\
\text { Composition }\end{array}$ & $\begin{array}{l}\mathrm{SiO}_{2} \\
(\%)\end{array}$ & $\begin{array}{l}\mathrm{Al}_{2} \mathrm{O}_{3} \\
(\%)\end{array}$ & $\begin{array}{l}\mathrm{MgO} \\
(\%)\end{array}$ & $\begin{array}{l}\mathrm{Na}_{2} \mathrm{O} \\
(\%)\end{array}$ & $\begin{array}{l}\mathrm{CaO} \\
(\%)\end{array}$ & $\begin{array}{l}\mathrm{Fe}_{2} \mathrm{O}_{3} \\
(\%)\end{array}$ & $\begin{array}{l}\mathrm{Cl} \\
(\%)\end{array}$ & $\begin{array}{l}\mathrm{P}_{2} \mathrm{O}_{5} \\
(\%)\end{array}$ & $\begin{array}{l}\mathrm{K}_{2} \mathrm{O} \\
(\%)\end{array}$ & $\begin{array}{l}\mathrm{LOI} \\
(\%)\end{array}$ \\
\hline $\begin{array}{c}\text { Glass } \\
\text { Powder } \\
\text { (GP) }\end{array}$ & 68.89 & 4.147 & 2.717 & 16.938 & 5.904 & 0.52 & 0 & 0 & 0.568 & 0.316 \\
$\begin{array}{c}\text { Palm Oil Fly } \\
\text { Ash (POFA) } \\
\text { Lime }\end{array}$ & 61.663 & 5.13 & 4.17 & 0.49 & 9.869 & 5.299 & 0.162 & 3.716 & 8.427 & 1.074 \\
\hline
\end{tabular}

\subsection{Material Preparation}

The prototype for sustainable bricks using locally available waste was developed using laboratory facilities. The newly developed bricks are referred to as Themally Efficient Sustainable Hybrid (TESH) bricks. The raw materials were pre-processed initially to meet the standard requirements for bricks. The glass powder and palm oil fly ash fineness were kept at $90 \mu \mathrm{m}$ to enhance the pozzolanic reactivity, whilst the crusher dust particle size was maintained below $2.38 \mathrm{~mm}$. The oil palm fibers were cleaned using alkali treatment. The ratios of raw materials were selected based on the Taguchi's method described in a previous research paper by Raut and Gomez [16]. The ratio for development of bricks is given in Table 1 . Water content was kept at 0.35 water content to the total weight of constituent materials except for weight of Oil Palm Fibers. The constituent materials were first dry mixed in a mixture machine, and subsequently wet mixed till the mixture attained homogeneity. The homogenous mixture thus obtained was inserted into a mould and further compacted by using a vibrating machine. After 24 hours, sufficiently hardened bricks were demoulded before proceeding with the curing procedure by immersing the specimens in water bath maintained at $20^{\circ} \mathrm{C}$. 


\subsection{Testing Procedure}

Various tests were conducted on the developed sustainable blocks as per required standards to validate it as a building material. The tests conducted on developed sustainable blocks were performed to determine and analyse the physical, mechanical and thermal characteristics. Water absorption, bulk density, and porosity tests were performed on the developed samples having size $210 \times 100 \times 100 \mathrm{~mm}^{3}$ as per the ASTM C20-00 (2015) [17] standard. Also, compression test was conducted as per standard ASTM C67-14 [18] by using compressive testing machine having a capacity of $3000 \mathrm{KN}$. The flexural strength of bricks were determined using universal testing machine of $10,000 \mathrm{KN}$ capacity as per IS 4860:1968 [19]. Determination of initial rate of suction was done as per BS 3921:1985 [20].

\section{Performance of sustainable blocks}

\subsection{Physico-Mechanical Performances}

The physical properties of bricks such as apparent porosity, water absorption, and bulk density are primary properties of building materials. These properties are widely used in the evaluation and comparison of product quality and as part of the criteria for selection and use for construction practices. The physical properties such as bulk density, water absorption, porosity and the initial rate of suction for the material are shown in Table 2. The bulk density observed for developed TESH bricks were comparatively lower that of commercially available clay bricks (refer Table 2). The reduction of bulk density is advantageous due to the fact that light weight bricks will eventually reduce the dead weight of the structure, thus reducing overall steel consumption for reinforcement. Thus, the reduction in dead weight of structure can be helpful in lowering construction cost of the structure. Also, low-density bricks are easy to handle and transport.

From the Table 2, it is evident that values for water absorption and the initial rate of suction are higher for developed TESH bricks compared to conventional fired clay bricks. The higher absorption rate can be attributed to the inclusion of oil palm fibers which enhances the apparent porosity. The high amount of water absorption is a matter of concern considering the durability aspect of materials. However, the developed brick seems to have water absorption within the range provided in IS standard for non-load bearing bricks. However, Malaysian Standard and British Standard does not specify any specific requirement for water absorption of bricks.

Table 2 Comparative analysis of physical performance of bricks

\begin{tabular}{ccccc}
\hline Materials & $\begin{array}{c}\text { Bulk Density } \\
\left(\mathbf{k g} / \mathbf{m}^{\mathbf{3}} \mathbf{)}\right.\end{array}$ & $\begin{array}{c}\text { Water Absorption } \\
\mathbf{( \% )}\end{array}$ & Porosity (\%) & $\begin{array}{c}\text { Initial Rate of } \\
\text { Suction (\%) }\end{array}$ \\
\hline TES H bricks & 1467.81 & 17.67 & 26.42 & 2.291 \\
\hline Fired clay bricks & 2118 & 5 & - & 0.2 \\
\hline
\end{tabular}


Mechanical performance analysis is necessary for understanding the load bearing capacity of structural and non-structural materials. Compressive strength is one of the critical parameters for determining the load bearing capability of the brick/mortar. Common minimum values for compressive strength for non-load bearing, and load bearing fired clay bricks are 3 to $5 \mathrm{Mpa}$ and 5 to $10 \mathrm{MPa}$ respectively. These bricks are in practice part of the brick wall system, and thus the analys is involves both tests on the brick as well as the brick and mortar as a brick wall system. The results of compressive strength tests and flexural strength tests for the TESH bricks that constitute the main part of the wall system are presented in Table 3 . The strength of developed TESH bricks is comparatively lesser than the commercially available fired red clay bricks. However, the compressive strength results for TESH bricks were found to be satisfactory as per MS 76: 1972 [21] and BS 3921: 1985[20] for load bearing bricks. This is found to be a non-issue as these bricks are designed for non-load bearing purpose for the low-cost house. The flexural strength results for developed bricks complies with AS/NZS 3700 [22], which recommends that bricks should have a flexural strength of 1 to $2 \mathrm{Mpa}$. The higher flexural strength of bricks restricts the propagation of cracks thus maintaining good quality.

Table 3 Mechanical properties of the materials used for TESH wall system

\begin{tabular}{ccc}
\hline Materials & $\begin{array}{c}\text { Compressive strength } \\
\text { (Mpa) }\end{array}$ & $\begin{array}{c}\text { Flexural Strength } \\
\text { (Mpa) }\end{array}$ \\
\hline TESH bricks & 7.23 & 1.62 \\
\hline Fired clay bricks & 25.65 & 1.97 \\
\hline
\end{tabular}

The bond strength between bricks and mortar plays a crucial role in mechanical performance of the wall as a whole system. However, the preparation of the fibre reinforced mortar (FRM) is not discussed in this paper, please refer to Raut and Gomez ( ????) for a complete verification of the performance of the developed FRM. FRM is included in this paper to provide further evidence of the capability of the TESH brick performing as part of the wall system. The wall system should have a perfect bond between its masonry unit and the mortar. This is essential for the masonry wall system to resist the stresses due to different types of loading conditions. To understand the bond between mortar and brick units, shear bond test was performed. The bond between brick units and mortar is mainly attributed to the mechanical inter-locking of cement hydration products into the surface pores of the bricks. The results of shear bond strength for TESH brick masonry system are shown in Table 4. The strength of the bond is found to be comparatively weaker than that of conventional brick mortar bond for clay brick wall system. The shear bond strength mainly depends upon a number of parameters relating to the brick and mortar characteristics. The water content required for bonding of brick and mortar also depends on the initial rate of suction of bricks. If the initial rate of suction is more the bricks might absorb more water from mortar layer, making the mortar layer dry thus lowering the bond. Another important parameter for bond strength is the compressive strength of the masonry units as well as mortar. 
Table 4 Result for shear bond strength test

\begin{tabular}{cc}
\hline Material & $\begin{array}{c}\text { Shear bond Strength } \\
\left(\mathbf{k g} / \mathbf{c m}^{2}\right)\end{array}$ \\
\hline TESH Wall & 2.9 \\
\hline Conventional Wall & 3.18 \\
\hline
\end{tabular}

\subsection{Thermal Performances}

The thermal performance of a material is mainly governed by the thermal conductivity, heat capacity, and density. The thermal conductivity for the TESH bricks was compared with the conventional bricks. The developed TESH brick shows lower thermal conductivity values (refer Table 5), which indicates the lowered heat transferred rate. Another important aspect of thermal performance is the materials heat capacity which is the energy required for a material to raise its temperature by $1^{\circ} \mathrm{c}$. The heat capacity of material is primarily determined by materials ability to store the heat. The heat capacity of material plays a major role in determining the thermal mass of wall system and also in the dynamic heat transfer process. The heat capacity of TESH bricks were determined by using Digital Scanning Calorimeter (DSC).

The thermal performance of materials for non-steady heat conditions require determination of thermal diffusivity $(\alpha)$ and thermal effusivity $(e)$. Thermal diffusivity of material is helpful in understanding the thermal inertia within the material. Thermal diffusivity is the thermophysical property that defines the speed of heat propagation by conduction during changes of temperature. The higher the thermal diffusivity, the faster the heat propagation. The thermal diffusivity is related to the thermal conductivity, specific heat capacity, and density. The formula for determining the thermal diffusivity $(\alpha)$ is given in Equation 5.1

$$
\alpha=\frac{\lambda}{\operatorname{Cp} \times p}
$$

Where,

$$
\begin{aligned}
\alpha & =\text { Thermal Diffusivity }(\mathrm{m} 2 / \mathrm{s}) \\
\lambda & =\text { Thermal Conductivity }(\mathrm{W} / \mathrm{m} . \mathrm{K}) \\
\mathrm{Cp} & =\text { Heat Capacity }\left(\mathrm{J} / \mathrm{kg}^{\circ} \mathrm{c}\right) \\
\rho & =\text { Density }(\mathrm{kg} / \mathrm{m} 3)
\end{aligned}
$$

From Table 5, it is evident that the TESH bricks shows lower thermal diffusivity values as compared to the conventional bricks. Thus, it can be concluded that the rate of heat propagation in TESH wall system is slower as compared to the conventional wall system. 
Table 5 Thermal properties of the materials used for TESH bricks

\begin{tabular}{|c|c|c|c|c|c|}
\hline Materials & $\begin{array}{c}\text { Thermal } \\
\text { conductivity } \\
(\mathrm{W} / \mathrm{m} . \mathrm{K})\end{array}$ & $\begin{array}{c}\text { Heat } \\
\text { capacity } \\
\left(\mathrm{J} / \mathrm{kg}^{0} \mathrm{c}\right)\end{array}$ & $\begin{array}{c}\text { Thermal } \\
\text { diffusivity } \\
\left(\mathrm{m}^{2} / \mathrm{s}\right)\end{array}$ & $\begin{array}{c}\text { Thermal } \\
\text { effusivity } \\
\left(\mathrm{WK}^{-1} \mathrm{~m}^{-2}\right. \\
\left.\mathrm{s}^{1 / 2}\right)\end{array}$ & $\begin{array}{c}\text { Thermal } \\
\text { Resistance } \\
\left(\mathrm{m}^{2} \mathrm{~K} / \mathrm{W}\right)\end{array}$ \\
\hline TESH bricks & 0.3812 & 1152 & $2.254 \times 10^{-7}$ & 802.85 & 0.262 \\
\hline $\begin{array}{c}\text { Conventional } \\
\text { Brick Layer }\end{array}$ & 0.72 & 840 & $4.45 \times 10^{-7}$ & 1079 & 0.138 \\
\hline
\end{tabular}

Whereas, thermal effusivity (heat penetration coefficient) is the rate at which a material can absorb heat, lower the thermal effusivity better the thermal performance of building material to provide comfort condition. The thermal effusivity depends on the thermal conductivity, specific heat capacity, and density same as that of thermal diffusivity. The formula for determining the thermal effusivity $(e)$ is given in Equation 5.2.

Where,

$$
e=\frac{1}{\lambda \times[\mathrm{p} \times \rho}
$$

$$
\begin{aligned}
& e=\text { Thermal Effusivity }\left(\mathrm{WK}^{-1} \mathrm{~m}^{-2} \mathrm{~s}^{1 / 2}\right) \\
& \lambda=\text { Thermal Conductivity }(\mathrm{W} / \mathrm{m} \cdot \mathrm{K}) \\
& \mathrm{Cp}=\text { Heat Capacity }\left(\mathrm{J} / \mathrm{kg}^{\mathrm{o}} \mathrm{c}\right) \\
& \rho \quad=\text { Density }\left(\mathrm{kg} / \mathrm{m}^{3}\right)
\end{aligned}
$$

From Table 5.6, it is evident that the optimal proportion of fiber reinforced mortar and TESH bricks shows lower thermal effusivity values as compared to the conventional mortar and bricks. Thus, it can also be concluded that TESH wall system has lower heat absorption rate as compared to conventional wall system, which in a key aspect in providing comfort condition within the building envelope.

\section{Conclusions}

A comprehensive study on the developed TESH bricks using locally waste materials was conducted. The following conclusions were drawn from this research work:

1. The utilization locally available waste material to develop an alternative building material contributes towards the sustainability aspect of a building material.

2. The results fond that the developed bricks are lighter in weight than conventional burnt clay bricks. However, water absorption and porosity was on the higher side.

3. Compressive strength complies with MS 76: 1972 and BS 3921: 1985 for load bearing bricks. Also, flexural strength was also found to be slightly lower than the conventionalbricks. The results of shear bond strength showed good bonding with mortar having values in the range of conventional bricks.

4. Thermal conductivity of the TESH bricks was found to be around $50 \%$ lower than conventional bricks. Whereas, other thermal properties indicates towards the better thermal performance of TESH bricks over conventional bricks.

5. Overall, the developed TESH bricks are sustainable, light weight, thermally efficient and comply with the standard practices and therefore can be used as an alternative to conventional building material. 


\section{References}

1. Chan, Albert PC, and Ada PL Chan. "Key performance indicators for measuring construction success." Benchmarking: an international journal 11.2 : 203-221. (2004).

2. Government of Malaysia. Ninth Malaysia Plan (2006-2010). Putrajaya, Malaysia: Economic Planning Unit. (2006).

3. U.R. Abdulazeez, \& C.P. Gomez, "Effect of spatial design modification on Malaysian low-cost residential property value: a hedonic price model”, J. Teknologi, 76(1), pp. 367-372. (2016).

4. Raut, A. Narendra, and C. P. Gomez. "Development of thermally efficient fibrebased eco-friendly brick reusing locally available waste materials." Constr. Build. Mater. 133 : 275-284. (2017).

5. J. E. Oti, J. M. Kinuthia, \& J. Bai, " Design thermal values for unfired clay bricks". Mater. Design, 31(1), pp. 104-112. (2010).

6. J. Khedari, P. Watsanasathaporn, \& J. Hirunlabh, "Development of fibre-based soil-cement block with low thermal conductivity. Cement Concrete Comp, 27(1), pp. 111-116. (2005).

7. P. Turgut, "Fly ash block containing limestone and glass powder wastes. KSCE J Civ. Eng. , 17(6), pp. 1425-1431. (2013).

8. H. Binici, O. Aksogan, M.N. Bodur, E. Akca, \& S. Kapur, "Thermal isolation and mechanical properties of fibre reinforced mud bricks as wall materials". Constr. Build. Mater., 21(4), pp. 901-906. (2007).

9. A.H. Alami, "Mechanical and thermal properties of solid waste-based clay composites utilized as insulating materials". Int. J. of Therm. Env. Eng., 6(2), pp. 89-94. (2013).

10. H. Bal, Y. Jannot, S. Gaye, \& F. Demeurie, "Measurement and modelisation of the thermal conductivity of a wet composite porous medium: Laterite based bricks with millet waste additive". Constr. Build. Mater., 41, pp. 586-593. (2013).

11. J. Zach, J. Hroudová, M. Sedlamjer, "Possibilities of development of advanced ceramic blocks for external masonry structures of low energy and passive constructions". Proceedings of $3^{\text {rd }}$ International Conference on Sust. Mater. Tech., Kyoto, Japan. (2013).

12. C. Lertsatitthanakorn, S. Atthajariyakul, \& S. Soponronnarit, "Techno-economical evaluation of a rice husk ash (RHA) based sand-cement block for reducing solar conduction heat gain to a building". Constr. Build. Mater., 23(1), pp. 364-369. (2009).

13. Japanese Standard Association. "Testing method for thermal conductivity of insulating fire bricks by hot wire". JIS, 2618, pp. 3-4. (1992).

14. P. Meukam, Y. Jannot, A. Noumowe, \& T.C. Kofane,. "Thermo physical characteristics of economical building materials. Constr. Build. Mater., 18(6), pp. 437-443. (2004).

15. K.S. Wang, J. Chiou, C.H. Chen, \& D. Wang, "Lightweight properties and pore structure of foamed material made from sewage sludge ash". Constr. Build. Mater., 19(8), pp. 627-633. (2005).

16. Raut, A. Narendra, and P.C. Gomez. "Optimization of Mix Design of Thermally 
Efficient Blocks Using the Process Parameter Approach." J Mater. Civil Eng. (2016).

17. Standard ASTM. Standard Test Methods for Apparent Porosity, Water Absorption, Apparent Specific Gravity, and Bulk Density of Burned Refractory Brick and Shapes by Boiling Water. West Conshohocken, PA.: ASTM C20-00. (2015).

18. Standard ASTM. Standard Test Methods for Sampling and Testing Brick and Structural Clay Tile. West Conshohocken, PA.: ASTM C67-14. (2014).

19. Indian Sandard. Specification for acid resistant bricks. Bureau of Indian Standard, New Delhi. IS:4860. (1996).

20. British Standard. Specification for clay bricks. United Kingdom. BS 3921. (1985).

21. Malaysian Standard. Specifications for bricks and blocks of fired brickearth. (1972).

22. Australian/ New Zealand Standard. Masonry units and Segmental Pavers -Methods of test Method Determining Initial Rate of Absorption (suction). AS/NZS 4456.17. (1997). 